\title{
JClic Edilim: programas de autor para el diseño de actividades educativas en soporte digital para educación infantil y primaria
}

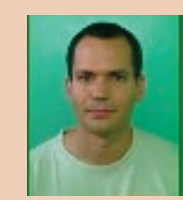

Raúl Tárraga Mínguez

Profesor Contratado Doctor del Departamento de Didáctica y Organización Escolar de la Universitat de València raul.tarraga@uv.es

\section{Los programas de autor}

Los programas de autor en educación son herramientas que permiten a los docentes el diseño de actividades educativas en soporte digital de un modo relativamente sencillo, y con unos resultados de calidad interesantes.

Bajo esta etiqueta de programas de autor se agrupa una notable variedad de programas cuyo funcionamiento es muy similar en casi todos los casos. El programa proporciona la estructura básica de cierto tipo de actividades educativas, y permite que cada docente personalice estas actividades dotándolas del contenido que le interese y adecuando el formato y la dificultad a las características de sus estudiantes. El producto final que se obtiene con estos programas son actividades educativas diseñadas por el propio docente, sin la necesidad de programar toda la estructura de la actividad partiendo desde cero, ya que la base sobre la que trabajar viene dada por el programa de autor.

Este funcionamiento convierte a los programas de autor en una herramienta interesante ya que permite al profesorado elaborar sus propios materiales educativos en soporte digital sin necesidad de tener elevados conocimientos informáticos y realizando un esfuerzo razonable y proporcional a los resultados obtenidos. Además, esta lógica basada en proporcionar herramientas para que los docentes creen sus propios materiales invierte el modelo más o menos generalizado e impuesto en nuestro sistema educativo en el que el docente es el consumidor final de productos educativos digitales que son comercializados por las grandes compañías editoriales, o de productos educativos recopilados por la administración y clasificados en repositorios educativos (Peirats y San Martín, 2011)
Existen múltiples ejemplos de programas de autor para educación: Atenex, desarrollado por la Consejería de Educación de Extremadura; Cuadernia, desarrollado por la Consejería de Educación de Castilla-La Mancha; Rayuela, desarrollado por el Instituto Cervantes; MALTED, desarrollado por el Instituto de Tecnología Educativa del Ministerio de Educación de España; Hot Potatoes, desarrollado por la University of Victoria (Canadá), etc. Todos estos programas se distribuyen con diferentes licencias de uso gratuito.

En el presente artículo se analizarán dos de los programas que más difusión tienen en los centros de educación infantil y primaria, y que ofrecen además posibilidades interesantes para el diseño de actividades educativas para estudiantes con necesidades educativas especiales: JClic, desarrollado por Francesc Busquets, y alojado en la web del Departamento de Universidades, Investigación y Sociedad del Conocimiento de la Generalitat de Cataluña, y EdiLim, desarrollado por Fran Macías, y alojado en la web del mismo autor Educalim.

\section{Diseño de actividades educativas con JClic} JClic es uno de los programas educativos más conocidos y empleados en los centros educativos en España, gracias al enorme repositorio de actividades que ofrece, a su uso gratuito, y a que el programa viene incluido en algunas de las principales distribuciones de Linux que las administraciones educativas españolas están generalizando en los centros escolares (como Lliurex en la Comunitat Valenciana).

JClic se compone de los programas JClic Player, que permite abrir y jugar con actividades ya elaboradas, JClic Re- 


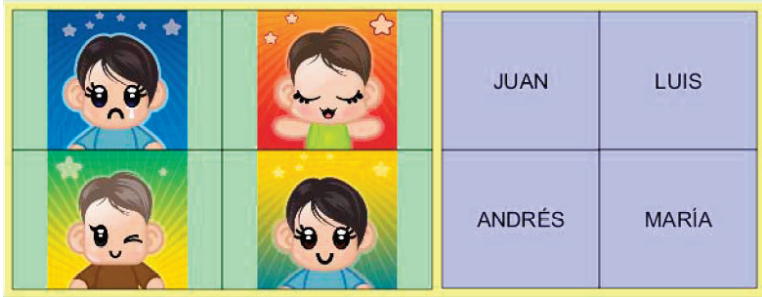

Figura 1. Actividad de asociación elaborada con Jclic.

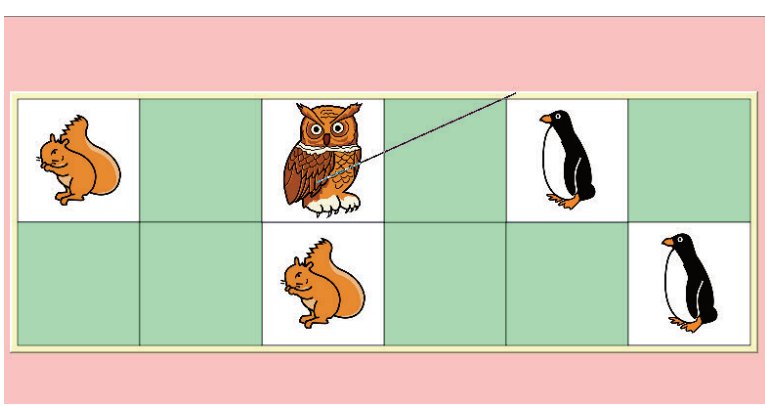

Figura 2. Juego de memoria elaborado con Jclic.

ports, que permite registrar los informes de actividad de los estudiantes una vez han realizado las actividades, y JClic Author, que es el programa que permite diseñar las actividades.

JClic Author permite diseñar 17 tipos de actividades. A continuación se exponen algunas de ellas.

Actividades de asociación simple y compleja. Son dos de los tipos de actividades más usuales en JClic. En estas actividades se presentan dos paneles divididos en diferentes casillas con contenido de imágenes, sonidos, texto, vídeo o la combinación de varios de estos elementos. La tarea de los estudiantes consiste en relacionar las casillas de uno y otro panel de acuerdo al contenido de las mismas y a las instrucciones dadas.

Juegos de memoria. En este tipo de juegos aparece un panel dividido en casillas cuyo contenido está oculto. Los estudiantes deben ir descubriendo una a una cada casilla, y recordar su contenido para emparejar las casillas con el mismo contenido.

Actividades de identificación. En estas actividades aparece un panel dividido en casillas con diferente contenido. Los estudiantes deben seleccionar sólo las casillas que cumplan una determinada condición de acuerdo a las instrucciones ofrecidas.

Puzle doble, de intercambio y de agujero. Son tres tipos de actividades en las que los estudiantes deben realizar puzles, bien traspasando las piezas de un panel a otro (puzle doble), bien ordenándolas dentro de un único panel (puzle de intercambio), o bien ordenando las piezas en un único panel con la dificultad de que falta una de las piezas (puzle de agujero).

Actividades de texto: completar texto, rellenar agujeros, identificar elementos y ordenar. En estas actividades predomina el componente textual. Los estudiantes deben completar determinadas partes que se han suprimido (completar texto y rellenar agujeros), ordenar partes de una palabra, frase o texto (ordenar elementos), o identificar partes determinadas de un texto (identificar elementos).

Actividades de respuesta escrita. En estas actividades los estudiantes deben teclear la respuesta a las preguntas planteadas (son las únicas actividades en JClic que exigen el uso del teclado).

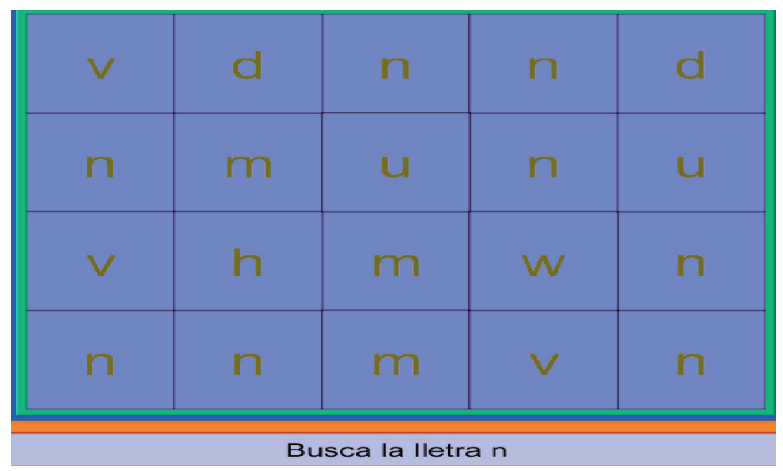

Figura 3. Actividad de identificación elaborada con Jclic.

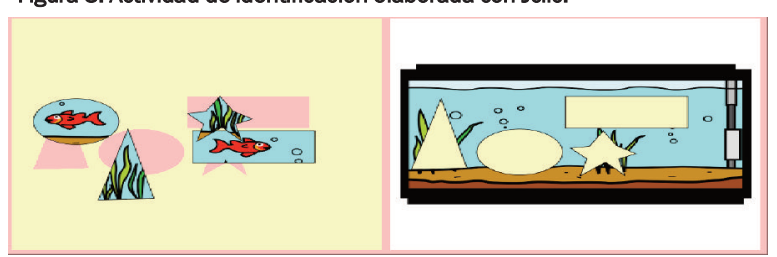

Figura 4. Puzle elaborado con JClic.

Sopas de letras y crucigramas. Son actividades que permiten diseñar de un modo sencillo sopas de letras o crucigramas.

Actividades de aritmética. Finalmente, este tipo de actividades permite generar aleatoriamente operaciones aritméticas sencillas (sumas, restas, multiplicaciones y divisiones) de acuerdo a unos parámetros de dificultad que determinemos (tamaño de los operandos, decimales, etc.)

\section{Diseño de actividades educativas con EdiLim}

El Editor de Libros Interactivos Multimedia (EdiLim) es un programa que hasta el momento no ha alcanzado la difusión y popularidad de JClic, probablemente debido a que su repositorio de actividades es bastante más modesto. Sin embargo, ofrece prestaciones muy interesantes: tiene una versión portable que podemos utilizar sin necesidad de instalar el programa en nuestro ordenador, la exportación a formato html de las actividades permite incluirlas con facilidad en blogs o sitios web y en la última versión del programa se permite la posibilidad de diseñar hasta 51 tipos de páginas diferentes. Muchas de estas páginas son similares a las que ofrece JClic, como las páginas de puzles, sopas de letras, juegos de memoria, actividades de asociación, de respuesta escrita, o de identificación de elementos, por lo que podríamos afirmar que EdiLim contiene prácticamente todas las actividades de Jclic, pero además las amplía con una notable cantidad de nuevas actividades. A continuación se resumen algunas de ellas.

Páginas de respuesta múltiple. Este tipo de actividades permite el diseño de preguntas en que los estudiantes deben escoger una respuesta entre varias propuestas.

Páginas de etiquetas. En este tipo de páginas los estudiantes deben colocar una serie de etiquetas en las partes correspondiente.

Páginas de clasificación de imágenes y textos. En este tipo de actividades se presenta una serie de imágenes o textos, y dos contenedores de elementos correspondientes a dos categorías de elementos. Los estudiantes deben colocar las imágenes o textos en la categoría correspondiente.

Páginas de uso del reloj. En este tipo de páginas los estudiantes deben escribir la hora que indica un reloj, o bien deben colocar en el reloj la hora que se indica en un texto. 
Escoge la respuesta correcta

¿Qué animal nos despierta por las mañanas?

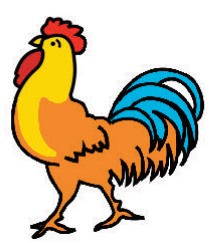

1 El gallo

2 El canguro

3 La cigüeñ

Figura 5. Página de respuesta múltiple elaborada con EdiLim. Coloca las etiquetas en el lugar correspondiente
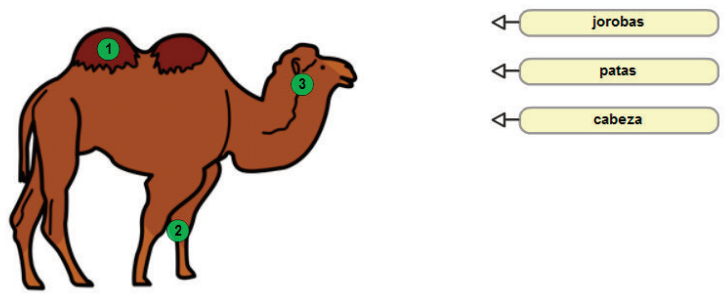

Figura 6. Página de etiquetas elaborada con EdiLim.

Página de palabra secreta. En estas actividades los estudiantes deben adivinar una palabra escondida a partir de una definición, y seleccionando letras del abecedario. Es similar al tradicional juego del ahorcado.

Página de dictado. En estas actividades se activa un sonido, que el estudiante debe escribir con el teclado imitando un dictado tradicional.

\section{Conclusiones}

Tras la revisión de JClic y EdiLim, extraemos las siguientes conclusiones:

- Ambos programas tienen la virtud de que permiten diseñar una interesante variedad de tareas educativas sin necesidad de poseer elevados conocimientos informáti-

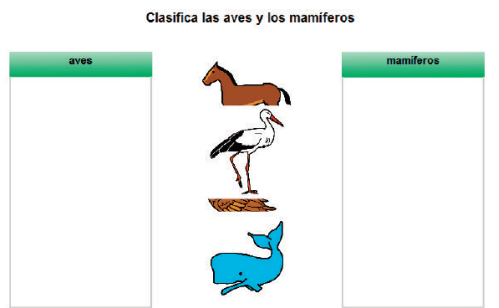

Figura 7. Página de clasificación de imágenes elaborada con EdiLim.

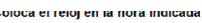

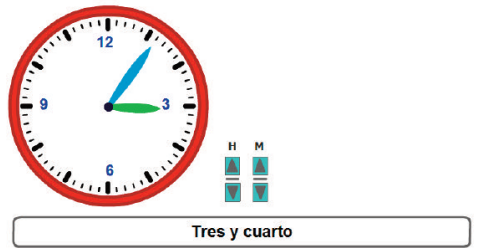

Figura 8. Página de juego de reloj elaborada con EdiLim.

cos, con baja inversión de tiempo, y con resultados interesantes para el trabajo en el aula.

- Las características y el nivel de dificultad de las actividades que pueden diseñarse con estos programas convierten a JClic y EdiLim en herramientas apropiadas para el trabajo en las etapas de educación infantil y educación primaria, así como para el trabajo con estudiantes con necesidades educativas especiales. En niveles educativos superiores, aunque pueden diseñarse proyectos interesantes, este tipo de tareas pueden resultar menos adecuadas dada su sencillez y su carácter básicamente procedimental, por lo que será conveniente recurrir a otras herramientas (webquests, trabajo en redes sociales, etc.).

- Pese a que JClic es uno de los programas más populares y de uso más generalizado, EdiLim ofrece la posibilidad de diseñar las mismas actividades que JClic, y además añade nuevos tipos de actividades no contemplados en JClic.

- Finalmente, dada la facilidad y prestaciones de estos programas, sería interesante que su uso y análisis se incluyera en los planes de estudio de formación de maes-

\begin{tabular}{|c|l|l|}
\hline & \multicolumn{1}{|c|}{ JClic } & \multicolumn{1}{|c|}{ EdiLim } \\
\hline $\begin{array}{c}\text { Licencia de uso } \\
\text { Licencia Pública General de GNU. }\end{array}$ & $\begin{array}{l}\text { No se especifica, aunque se indica que EdiLim es } \\
\text { gratuito para cualquier tipo de uso, pero no se } \\
\text { permitide modificar el código fuente sin } \\
\text { autorización. }\end{array}$ \\
\hline $\begin{array}{c}\text { Idiomas a los que } \\
\text { se ha traducido la } \\
\text { interfaz }\end{array}$ & $\begin{array}{l}\text { Alemán, asturiano, castellano, catalán, euskera, } \\
\text { francés, gallego, griego, inglés, italiano, neerlandés, } \\
\text { portugués, ruso, y turco (entre otros). }\end{array}$ & $\begin{array}{l}\text { Alemán, asturiano, castellano, catalán, euskera, } \\
\text { francés, gallego, inglés, italiano, y portugués } \\
\text { (entre otros). }\end{array}$ \\
\hline Plataformas & Linux, Mac, Solaris, Windows. & Linux, Windows. \\
\hline $\begin{array}{c}\text { Requerimientos } \\
\text { Formatos de las } \\
\text { actividades }\end{array}$ & $\begin{array}{l}\text { Requiere tener instalado sistema Java. } \\
\text { diseñar actividades. }\end{array}$ & $\begin{array}{l}\text { Puede descargarse una versión portable } \\
\text { (no requiere instalación). }\end{array}$ \\
\hline $\begin{array}{c}\text { Web de descarga el ordenador para } \\
\text { Permite exportar a html, o visualizar en formato jclic }\end{array}$ & $\begin{array}{l}\text { Permite exportar a html, o visualizar en formato } \\
\text { lime }\end{array}$ \\
\hline $\begin{array}{c}\text { Sitios web con } \\
\text { tutoriales }\end{array}$ & http://clic.xtec.cat/es/jclic/curs.htm & http://www.educalim.com/cdescargas.htm \\
\hline $\begin{array}{c}\text { Repositorio de } \\
\text { actividades }\end{array}$ & http://clic.xtec.cat/db/listact_es.jsp & http://www.educalim.com/ccrear.htm \\
\hline
\end{tabular}

Tabla 1. Comparación de las características básicas de JClic y EdiLim. 
tros de educación infantil y primaria, ya que los programas de autor pueden convertirse en una herramienta de uso cotidiano del profesorado.

\section{Bibliografía}

Peirats, Jose; San Martín, Angel (2011). Tecnologías educativas 2.o. Didáctica de los contenidos digitales. Madrid: Pearson.

| Cita recomendada de este artículo

Tárraga Mínguez, Raúl (2012). JClic y Edilim: programas de autor para el diseño de actividades educativas en soporte digital para educación infantil y primaria. @tic. revista d'innovació educativa. ( $n^{\circ} 9$ ) [Evaluación de herramientas] URL. Fecha de consulta, dd/mm/aaaa. 